\title{
Aspectos da complexidade nas questões socioambientais: as abordagens no Brasil e na Espanha
}

\author{
Aspects of complexity in social-environmental issues: \\ the approaches in Brazil and Spain
}

\author{
Giselle Watanabe ${ }^{1}$ \\ https://orcid.org/0000-0002-3738-7160 \\ Fátima Rodríguez-Marín ${ }^{2}$ \\ https://orcid.org/0000-0003-0771-6944
}

\begin{abstract}
Resumo: As questões socioambientais promovem discussões abertas e complexas, podendo aproximar estudantes de suas realidades, o que, por sua vez, traz distintos significados para a aprendizagem escolar. Considerando essas potencialidades, este artigo traz um panorama da perspectiva da complexidade nas produções socioambientais em ensino no Brasil e na Espanha. Metodologicamente, apresentam-se os níveis de ensino nos dois países e alguns documentos que orientam a Educação Ambiental para, em seguida, investigar de que forma os trabalhos acadêmicos publicados em revistas reconhecidas do ensino vêm abordando a perspectiva da complexidade na temática socioambiental. Dos resultados, identifica-se uma gama considerável de produções com potencial para abordar a complexidade, seja em uma perspectiva com (i) aproximações pontuais; (ii) potencial: em transição; ou, (iii) alto potencial: consolidada. Particularmente, as produções em (iii) estão mais próximas da perspectiva da complexidade enquanto elemento organizador da Dimensão Educacional, da Dimensão Ensino-Aprendizagem e da Dimensão Epistemológica.
\end{abstract}

Palavras-chave: Educação ambiental. Processo social. Complexidade. Espanha. Brasil.

\begin{abstract}
Environmental issues may promote open and complex discussions bringing students closer to their realities and different meanings for school learning. This research overviews the complexity in Science Teaching outcomes in Brazil and Spain. Beyond the research for results about different conceptions, it attempted to understand the approaches of these productions focused on environmental matters and the potential to promote a complex reading of the world. Methodologically, it presents levels of education, documents guiding Environmental Education in both countries, and investigates the works published in journals about complexity in socio-environmental issues. From the results, it was acknowledged that a range of approaches to the complexity perspective exists, it could be in a perspective of (i) punctual approximations; (ii) potential - in transition; (iii) high potential - consolidated. Particularly, productions in (iii) are closer to complexity as organizing element of Educational Dimension, Teaching-Learning Dimension and Epistemological Dimension.
\end{abstract}

Keywords: Environment education. Social process. Complexity. Spain. Brazil.

\footnotetext{
${ }^{1}$ Universidade Federal do ABC, Santo André, SP, Brasil. E-mail: < giselle.watanabe@ufabc.edu.br>.

${ }^{2}$ Universidad de Sevilla, Departamento de Didáctica de las Ciencias Experimentales y Sociales, Sevilla, España.
} 


\section{Introdução}

Nas últimas décadas, a busca por uma educação mais crítica ganhou importância nas escolas e instituições de pesquisas. De certo modo, isso promoveu mudanças nos currículos e deu margem, ainda que limitada, para que uma outra forma de apresentar os conhecimentos científicos escolares fosse proposta. Essa demanda também trouxe novos desafios para a escola tal como a necessidade de promover um ensino que forme cidadãos e cidadãs capazes de atuar frente aos problemas de suas comunidades. Uma questão que se coloca a partir daí refere-se a qual realidade deve ou pode ser levada para a sala de aula. Para nós, parece essencial considerar, como orientadores, aspectos da sociedade de risco (BECK, 1997) e da complexidade (GARCÍA, 1998; MORIN, 2007), de forma que sejam reconhecidas a imprevisibilidade e ameaças provocadas pelo desenvolvimento técnico-industrial. Encarar o mundo desse ponto de vista exige novos posicionamentos que, de antemão, podem levar os indivíduos à autorreflexão em relação às bases que sustentam as sociedades. No contexto escolar, essa ideia pode traduzir ações que promovam uma Educação Ambiental (EA) pautada em uma visão mais complexa, menos determinista e simplificadora (MORIN, 2007; PRIGOGINE, 1996) sobre o mundo.Uma EA mais complexa prescinde de espaços escolares que potencializam uma gestão ambiental compatível com as mudanças demandadas. Nesse sentido, encontrá-los requer também identificar as principais ideias sobre EA presentes nos documentos de órgãos reguladores, considerando o processo de ensino-aprendizagem (níveis de ensino) dos países estudados. No caso do Brasil e da Espanha, o sistema de ensino se distingue especialmente após os 15 anos de idade: no Brasil propõe-se o Ensino Médio ou Técnico/Profissional; na Espanha, o Técnico/Profissional, Bachillerato (com foco no Ensino Superior) ou formação para o mundo do trabalho. A Figura 1 traz um comparativo dos níveis de ensino dos dois países, organizados a partir das idades dos(as) estudantes.

Figura 1. Comparativo dos níveis de ensino no Brasil e Espanha

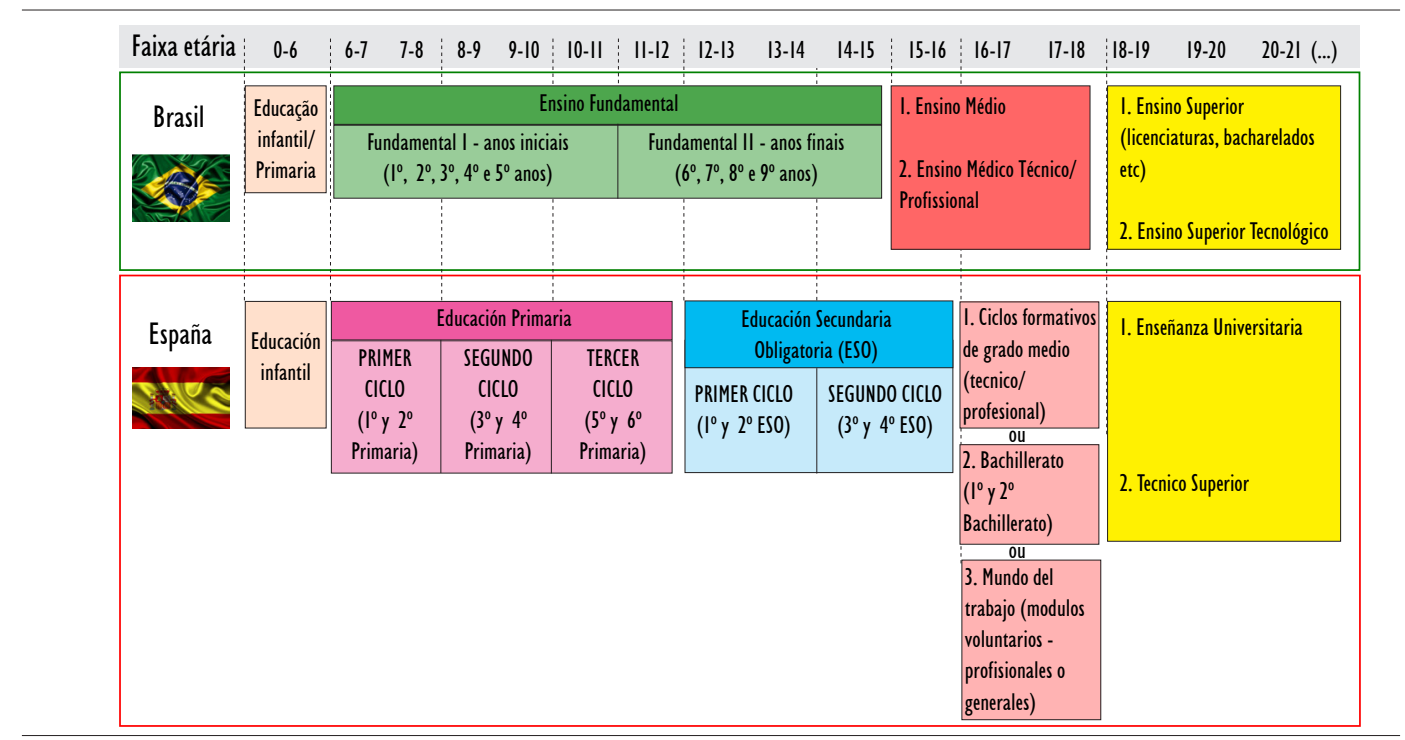

Fonte: elaborado pelas autoras. 
No que se referem aos documentos, no Brasil a formação para a EA está atribuída ao longo de todo o ciclo formativo. Na Política Nacional de Educação Ambiental (PNEA) salientase que ela deve estar presente em diferentes níveis do ensino assim como em distintos espaços. Especificamente, o artigo $2^{\circ}$ da Lei n. 9.795, de 1999, explicita que "A educação ambiental é um componente essencial e permanente da educação nacional, devendo estar presente, de forma articulada, em todos os níveis e modalidades do processo educativo, em caráter formal e não-formal" (BRASIL, 1999). Em continuidade à PNEA, outros documentos foram produzidos, a exemplo do decreto federal $n^{\circ} 4.281$, de 25 de junho de 2002, que regulamenta tanto a PNEA quanto os Parâmetros Curriculares Nacionais (PCN) para os ensinos Fundamental e Médio (BRASIL, 2000, 2002). Os PCN apontam para a importância do trabalho com temas socioambientais, seja de forma transversal no Ensino Fundamental ou remontando uma visão interdisciplinar, no Ensino Médio (EM). Nos PCN+ para o EM (BRASIL, Ministério da Educação, 2002) a questão comparece ao discutir a contextualização do ensino de Ciências, especificamente, ao tratar dos impactos ambientais e custos financeiros e sociais considerando as formas de obtenção de energia. Outro documento acerca do assunto é de responsabilidade da coordenação geral de EA do Ministério da Educação, identificado como Resolução n ${ }^{\circ}$, de 15 de junho de 2012. Nele estabelecem-se as Diretrizes Curriculares Nacionais para a EA que, dentre outras coisas, procura

[...] estimular a reflexão crítica e propositiva da inserção da Educação Ambiental na formulação, execução e avaliação dos projetos institucionais e pedagógicos das instituições de ensino, para que a concepção de Educação Ambiental como integrante do currículo supere a mera distribuição do tema pelos demais componentes. (BRASIL, 2012, p. 2).

$\mathrm{Na}$ Espanha, também nota-se a preocupação de inserção da EA em todo o ciclo formativo. Parte dos documentos que tratam do assunto foi analisada pelo projeto Erasmus Plus ${ }^{3}$, que inclui uma das autoras deste artigo. Dessa análise, foram abordados onze documentos, dentre os quais: Ley Orgánica 2/2006, de 3 de maio, de Educación (LOE) (ESPANHA, 2006); Ley Orgánica 8/2013, de 9 de dezembro, para a melhora da qualidade educativa (LOMCE) (ESPANHA, 2013); Decreto 428/2008, de 29 de julho, que estabelece a organização e ensino da Educação Infantil em Andaluzia (ESPANHA, 2008); Ordem de 10 de agosto de 2007, que desenvolve o currículo mínimo da Educação Primária de Andaluzia (ESPANHA, 2007); e Ordem de 17 de março de 2015, que trata do currículo correspondente para a Educação Primária em Andaluzia (ESPANHA, 2015). De forma geral, esses documentos indicam que o conceito de sustentabilidade no currículo da Educação Infantil aparece associado ao conhecimento dos componentes básicos do meio natural e algumas relações que se produzem entre eles, com foco

\footnotetext{
${ }^{3}$ Resultado parcial do projeto Erasmus Plus, denominado "Pedagogia della cittadinanza e formazione degli insegnanti: un'alleanza tra scuola e territorio" (Citizenship pedagogy and teacher education: an alliance between school, territory, community/ School Territory Environment Pedagogy) (referência 2015-1-IT02-KA201-015190 e financiado pela União Europeia).
} 
no cuidado e respeito ao ambiente. Há predominância do conteúdo de caráter procedimental e atitudinal frente aos aspectos conceituais. A sustentabilidade e os hábitos de consumo são considerados como temas transversais. Na Educação Primária, a sustentabilidade faz referência basicamente ao conhecimento da realidade natural, centrada no uso e disfrute do meio a serviço do homem e apostando em sua conservação e cuidado. Destacam-se que nos textos da comunidade andaluz, a visão de caráter mais descritivo e superficial é superada, dando espaço para análise das causas e consequências da intervenção humana no meio. No que se referem aos documentos curriculares (objetivos, conteúdos etc.) aparecem referências de forma isolada e independente, sem que se estabeleçam relações entre os mesmos.

Do ponto de vista dos documentos brasileiro e espanhol nota-se a defesa por uma EA mais crítica e que perpasse todos os níveis de ensino, sem que sejam assuntos enxertados nos currículos. No entanto, há de se considerar que essas indicações mais gerais demandam ações concretas na escola que, de antemão não se vinculem exclusivamente aos conceitos e tampouco estão atreladas aos projetos pontuais. Nesse sentido, cabe à escola promover uma formação na qual a realidade dos(as) estudantes esteja adequadamente explicitada, significando, por exemplo, tratar de temas vinculados aos contextos locais e globais (como os socioambientais), pautados em uma visão de mundo da complexidade (GARCÍA, 1998; MORIN, 2007). Esses temas, por sua própria natureza, apoiam-se em problemáticas mais abertas e dinâmicas.

Tomando a perspectiva da complexidade como uma primeira aproximação para promover mudanças nas formações básicas e pressupondo que as produções em ensino nos dois países podem apontar para tentativas nesse sentido (seja incorporando os discursos presentes nos documentos e/ou propondo ações nas escolas), nesse artigo propõe-se identificar a natureza dos debates presentes nos trabalhos publicados em periódicos brasileiros e espanhóis ${ }^{4}$, buscando elementos da complexidade nas proposições socioambientais.

\section{Elementos para um olhar sobre a complexidade}

Ao tratar da complexidade há de se considerar as distintas dimensões e interpretações que o conceito assume (CARVALHO, 2004; GARCIA, 1998; GUIMARAES, 2004; JACOBI, 2009; LEFF, 2009; LOUREIRO, 2006; MORIN, 2007; PRIGOGINE, 1996). Sem a intenção de identificar tais distinções, nesse artigo toma-se a complexidade como elemento organizador, considerando especialmente as interpretações de Morin (2007), García (1998) e Rodríguez-Marín e García (2009).

A complexidade refere-se a uma perspectiva de mundo na qual as relações no e entre os sistemas estão claramente evidenciadas, a ponto de se tornarem objetos da ciência (PRIGOGINE, 1996). Ela incorpora a parte da incerteza, o que gera e produz os seus riscos. Ela está atrelada às situações abertas e dinâmicas e, é por isso, que as questões socioambientais são tidas como potencializadoras para promoção da visão mais complexa.

\footnotetext{
${ }^{4} \mathrm{~A}$ opção por analisar as produções espanholas se dá pelo estabelecimento de grupos que vem tratando a complexidade nesse país, a exemplo do presente na Universidad de Sevilla. Considera-se ainda as aproximações dos autores que se devem fundamentalmente às congruências dos discursos teóricos, ganhando destaque a ideia de complexificação do conhecimento (GARCÍA, 1998).
} 
Para Rodríguez-Marín e García (2009) as questões socioambientais contemplam a complexidade de duas formas: implícita e explicitamente. A complexidade implícita, que aparece na maioria dos modelos de EA, corroboram para uma visão ativista, que implica em um olhar no qual: (i) a formulação e organização dos conteúdos não estão adequadamente explicitados, caracterizando-se por programas que apresentam tópicos de rotina; (ii) as estratégias empregadas e a lógica das atividades não tem um fio condutor claro, baseando-se em propostas pontuais que apresentam um desenvolvimento metodológico parcial, atomizado e aditivo; e (iii) o sentido que tem a atuação educativa para os participantes não está claro visto que o protagonismo do(a) aluno(a) se reduz a uma atividade mais manipulativa do que reflexiva. As principais características dos modelos ativistas referem-se aos modelos: (a) naturalista, (b) conservacionista; e (c) tecnocrático/ institucional.

$\mathrm{Na}$ complexidade explicita ganha destaque a perspectiva integradora (GARCÍA, 1998). Nela, o conhecimento escolar pauta-se na integração transformadora de diversas formas de conhecimentos, existindo uma continuidade entre os conhecimentos científico e cotidiano. Nesse contexto considera-se que a perspectiva da complexidade é

[...] uma atitude e um método, ou seja, uma busca de articulações e interdependências entre os conhecimentos, até agora divididos e compartimentalizados. Propõe-se uma mudança na nossa forma de compreender o universo, uma reorganização do saber e uma nova maneira de dirigir as indagações sobre o mundo. Representa uma atitude aberta, antirreducionista e relativizadora, que foge do dogmatismo e do uso de receitas simplificadoras, que admite a existência de incertezas, paradoxos e contradições. Supõe uma busca por novas maneiras de formular e enfrentar os problemas, mais que novas verdades que não explicam a realidade. (GARCÍA, 1998, p. 30).

A complexidade explícita pauta-se no paradigma da complexidade (MORIN, 2007) para formular e organizar os conteúdos escolares. Para isso defende: (i) concepção aberta, flexível e gradual do conteúdo; (ii) construção do conhecimento a partir de transições; (iii) relação de hierarquia e organização, explicitando os sistemas em interação; e (iv) busca por uma visão global, considerando os problemas socioambientais como organizadores curriculares. Especificamente em (ii), a complexidade é elemento fundamental para promover as transições. Essas transições pautam-se em determinados critérios, tal como presentes na Figura 2. A busca pela transição está em sair do mesocosmo e promover interações simultâneas entre ele, o micro e macrocosmo; em deixar a concepção estritamente aditiva em prol do entendimento dos sistemas; e em reconhecer os sistemas como complexos e promotores de diversidade. Essa transição conduz a causalidade complexa e promove co-evolução e reorganização dos sistemas de ideias.

Em (iii) a referência está nos conceitos metadisciplinares e no conhecimento metadisciplinar. O conhecimento metadisciplinar consiste em:

[...] a. um conhecimento sobre a natureza dos conhecimentos disciplinares e as análises histórica, sociológica e epistemológica dos conteúdos disciplinares [...]; b. cosmovisões ideológicas que determinam os sistemas de ideia que orientam o para que e o porquê das decisões que se tomam tanto no 
âmbito científico como no cotidiano ou no escolar; c. uma certa ontologia, que supõe a existência de entes complexos que podem descrever-se mediante noções transversais, transdisciplinares ou metadisciplinares, que são comuns a diversas disciplinas e que possuem um forte caráter estruturante dos diferentes campos do conhecimento. (RIVIERO, 1996 apud GARCÍA, 1998, p. 71-72).

Figura 2. Critérios para promoção das transições complexas
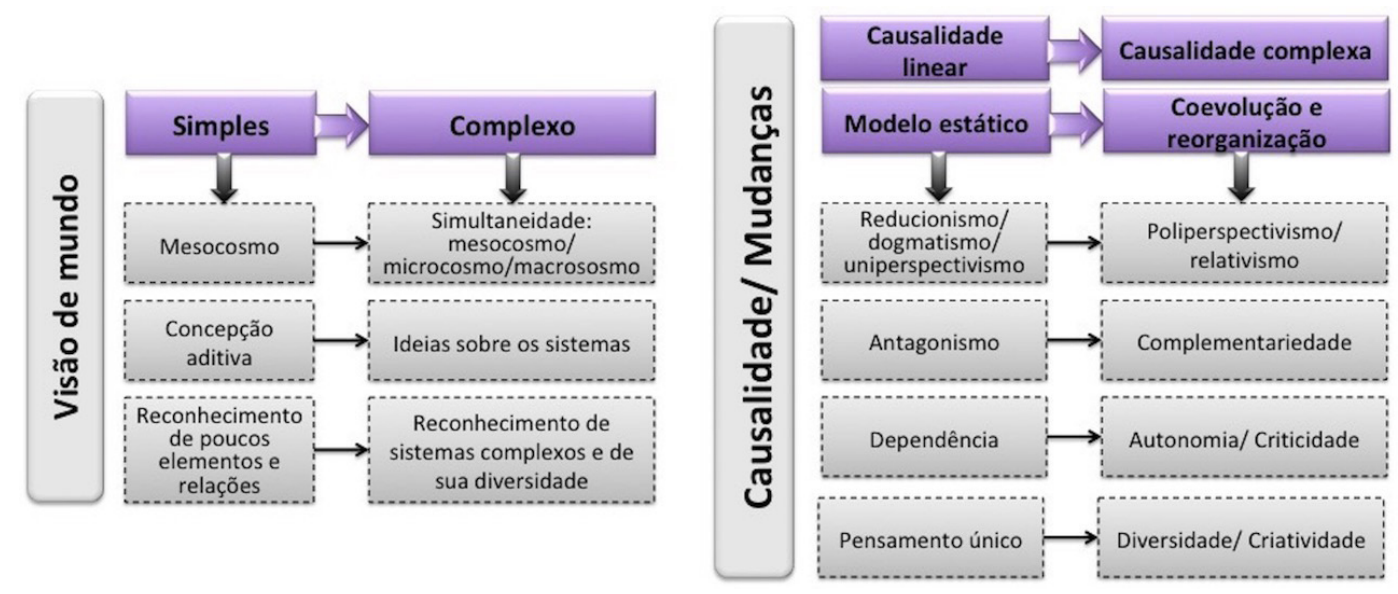

Fonte: adaptado de García (1998).

Em (iv) a discussão trata da natureza do conhecimento escolar, dando-lhe seu próprio status. Ou seja, não está subordinado nenhum outro conhecimento, tal como o científico. Considera o conhecimento escolar como aquele que integra as outras formas de conhecimento (científico, tecnológico, cultural etc.) e é enriquecido pelo conhecimento cotidiano, que apoia, desde uma perspectiva mais sistêmica, a continuidade entre as diferentes formas de conhecimento (GARCÍA, 1998).

Em (v) a abordagem trata dos âmbitos de intervenção dos(as) estudantes enquanto fundamentais para a organização da aprendizagem, considerando que os problemas devem relacionar o local e global; superar o antropocentrismo; promover tanto relações individuais quanto coletivas; explicitar os limites de crescimento dos sistemas; buscar a integração em prol do reducionismo (por exemplo, articular a perspectiva educativa - didática - com os conceitos sobre ambiente); integrar saberes incluindo um debate acerca da epistemologia da ciência; e promover a cosmovisão da complexidade. 


\section{Recorte metodológico}

O levantamento de dados realizou-se em duas etapas. Na primeira etapa, identificaram-se 128 trabalhos (61 espanhóis, 67 brasileiros) que abordam a complexidade nas questões socioambientais de forma mais geral, ou seja, apenas indicam o termo complexidade ao longo do texto. Na segunda etapa, a partir desse universo, foram selecionados aqueles que tratam da complexidade de forma mais detida, totalizando 41 trabalhos (21 espanhóis, 20 brasileiros). Esse procedimento em duas etapas se fez necessário visto que o discurso sobre a complexidade muitas vezes está implícito ou, quando explícito, pode apresentar uma abordagem ainda determinista e simplificadora. O Anexo A apresenta os 41 trabalhos potenciais à abordagem da complexidade.

A pesquisa realizou-se em revistas que aglutinam e divulgam as trabalhos em ensino no período de 2010 a 2016, e que são qualificadas pela WebQualis em Ensino (plataforma da Coordenação de Aperfeiçoamento de Pessoal de Nível Superior - CAPES). Em relação à WebQualis, optou-se por considerar as revistas estratificadas em A1 e A2, com exceção da revista Alambique (B1) que foi selecionada por conta da publicação de grupos de pesquisa de referência com enfoque na sala de aula e devido ao interesse na revista pelos pesquisadores espanhóis. $\mathrm{Na}$ Espanha foram analisadas: (R1) Enseñanza de las Ciencias; (R2) Revista Eureka sobre Enseñanza y Divulgación de las Ciencias; (R3) Alambique; e (R4) Investigación en la Escuela. No Brasil foram analisadas: (R5) Revista Brasileira de Pesquisa em Educação em Ciências (RBPEC); (R6) Ciência \& Educação; (R7) Investigações em Ensino de Ciências (IENCI); e (R8) Alexandria: Revista de Educação em Ciência e Tecnologia.

Devido às peculiaridades dos idiomas envolvidos, optou-se por utilizar palavras-chaves que denotem ideias muito próximas nos dois países. Na Espanha foram consideradas: educación medio ambiental (educación ambiental); medio ambiente; sostenibilidad (educación para la sostenibilidad); cambio climático; e contaminación. No Brasil foram consideradas: educação (socio)ambiental; ambiente; sustentabilidade; mudanças climáticas; e, contaminação. A opção por essas palavras deve-se à possibilidade de abordagens mais abertas e complexas. Assim, por exemplo, ao buscar por mudanças climáticas é possível encontrar discussões que tratem da alteração na dinâmica do planeta; ou ao considerar a contaminação é possível tratar dos problemas que envolvem os ciclos da água, $\mathrm{CO}_{2}$ dentre outros. Em ambos os casos, a temática conduz às questões socioambientais abertas e complexas.

As informações foram obtidas seguindo as ações: (a) localização das produções que apresentam no título, palavras-chave e resumo aspectos relacionados à discussão socioambiental e complexidade no contexto do ensino; (b) leitura na íntegra dos estudos selecionados; (c) identificação dos trabalhos com foco nas questões socioambientais e complexidade voltados ao ensino. As informações desse mapeamento foram analisadas por meio da Análise Textual Discursiva (MORAES; GALIAZZI, 2007), seguindo as etapas:

- unitarização: fragmentação de trechos dos estudos que fazem referência implícita ou explícita às questões socioambientais e complexidade no ensino de Ciências, emergindo assim, unidades de significado;

- categorias temáticas: agrupamento das unidades de significado segundo suas semelhanças semânticas;

- comunicação: elaboração de textos descritivos e interpretativos (metatextos) acerca das categorias temáticas. Com isso, cinco categorias foram identificadas, a saber: (C1) formação 
professor; (C2) discursos de estudantes, educadores(as) e/ou meios de comunicação; (C3) proposição de atividades e práticas educativas; (C4) planejamento e currículo; e (C5) reflexões teóricas.

\section{Aspectos da complexidade nas produções socioambientais brasileira e espanhola}

A análise que segue considera os trabalhos (T) que são potenciais à abordagem da complexidade. Alguns deles estão em mais de uma categoria, no entanto, para a análise optou-se por indicá-los na categoria que melhor justifica as ações/reflexões presentes na produção. Salientase que para cada categoria discutem-se somente algumas produções, tomadas como exemplos.

\section{C1: formação professor}

Nessa categoria encontram-se sete trabalhos (T9, T49, T50, T58, T85, T106 e T128) que discutem ações e intenções voltadas à formação de docentes, sendo implementadas ou frutos de reflexões. Em geral, os propósitos dessas produções tem por base uma formação mais crítica e significativa, tanto do(a) licenciando(a) quanto do(a) professor(a) em exercício, ampliando seus conhecimentos acerca das questões que envolvem a EA. Assim, por exemplo, T9 analisa a visão dos(as) licenciandos(as) do ensino Primário espanhol sobre a sustentabilidade. Cita a complexidade a partir de distintos documentos e grupos de referência, incluindo o Complex, da Universitat Autònoma de Barcelona. Destacam que trabalhar e viver com a complexidade implica no (1) reconhecimento da interação homem-natureza e seus efeitos; (2) conhecimentos que interrelacionam o meio com aspectos sociais, econômicos, ambientais etc.; e (3) conhecimento sobre o meio e problemáticas ambientais.

T85 discute as ideias dos(as) estudantes do "Máster Universitario en Profesorado de Secundaria Obligatoria, Bachillerato, Formación Profesional y Enseñanza de Idiomas" (módulos relacionados à formação de docentes). A complexidade aparece como foco de um dos grupos pesquisados e como referencial pontual para discutir o tema, tomando referências como Bonil, Junyent e Pujol, colaboradores do Còmplex.

T106 investiga as contribuições e limitações de um curso de formação de professores(as), tomando como referência a Educação para o Desenvolvimento Sustentável (EDS). Os autores discutem os documentos que balizam a EDS. Em um módulo do curso trata de assuntos como "A gênese e a essência da Educação para o Desenvolvimento Sustentável” e "A Década das Nações Unidas da Educação para o Desenvolvimento Sustentável”. A preocupação com a complexidade aparece pontualmente em dois momentos: uma resposta do professor, baseada em referenciais como Capra e Leff; e em um trecho do texto no qual há um alerta para a necessidade de se considerar a complexidade.

\section{C2: discursos dos(as) estudantes, educadores(as) e/ou meios de comunicação}

Nessa categoria encontram-se doze trabalhos (T6, T16, T17, T30, T31, T38, T42, T57, T68, T96, T107, T113) que discutem as ideias dos(as) estudantes e educadores(as) acerca de assuntos como meio ambiente, sustentabilidade e natureza. Aqui também estão presentes os discursos veiculados aos meios de comunicação. Assim, por exemplo, T6 analisa o processo de 
construção do conhecimento dos(as) alunos(as) sobre a água, tomando como dimensões de análise: evidente; multicausalidade; uniperspectivismo e pluriperspectivismo; e complexidade enquanto elementos e relações. Tem-se como referencial o grupo de professores e pesquisadores Investigación y Renovación Escolar (IRES).

T31 discute as questões socioambientais com alunos(as) do quarto curso da Educacíon Secundaria Obligatoria (ESO) em grupo de discussão, considerando sua pesquisa como investigação qualitativa. A complexidade aparece pontualmente ao citar Murillo na análise dos resultados. Nesse caso, salienta que "[...] la reintroducción de una especie, se caracteriza por la complejidad de los factores que intervienen y los diferentes puntos de vista desde los que puede ser abordado [...]" (T31, p. 89).

T38, semelhante ao T6 e T42, pesquisa as ideias dos(as) alunos(as) do primeiro curso do Bachillerato sobre a temática água, considerando os niveis de transição. Também trata os dados considerando tanto a complexidade quanto a multicausalidade, pautando-se em autores como García e Rivero, já supracitados nesse artigo.

T57 discute a prática pedagógica sobre EA de professores(as) de Química do EM. Destaca que os discursos analisados levam a uma concepção conservadora de EA. Nota-se aproximação do discurso dos participantes da pesquisa às classificações propostas por autores como Loureiro, Lima, Guimarães e Brügger. A complexidade aparece apenas nessa caracterização.

\section{C3: proposição de atividades e práticas educativas}

Nessa categoria apresentam-se seis trabalhos (T44, T47, T52, T75, T89 e T100) que propõem atividades para a sala de aula ou outras práticas educativas. Alguns desses trabalhos analisam ideias dos participantes para justificar a efetividade de suas proposições; outros buscam construir meios para avançar no entendimento da EA sendo, portanto, as intervenções propostas como forma de envolver os(as) alunos(as) nas discussões. Assim, por exemplo, T44 analisa as concepções e dificuldades dos(as) estudantes a partir de desenhos elaborados nas aulas sobre água e Terra. Apresentam um quadro (T44, p. 28) com as categorias e relações articuladas com os níveis de complexidade, tomando como referências principais Pozo e García.

T47 identifica as contribuições das abordagens sistêmicas em atividades de EA para estudantes da sétima série (produções de texto e reflexões sobre o consumo). Mostra que as atividades realizadas contribuíram para o desenvolvimento de concepções mais amplas sobre temáticas relacionadas à comunidade e questões globais. A complexidade aparece em diversos trechos da proposta, seja por meio do referencial teórico (Morin, Ludwig Von Bertallanffy, Kasper etc.) ou nas atividades propostas.

T52 analisa imagens, textos e discursos produzidos por estudantes, investigando possíveis sentidos controversos sobre efeitos socioambientais da exploração de petróleo. Salienta que as controvérsias revelam tensões que se complexificaram em interações discursivas. Em dois momentos a complexidade aparece de forma sutil e pouco articulada (T52, p. 88-92).

T100 identifica os interpretantes dos(as) alunos(as) ao se defrontarem com fotografias sobre maus tratos de animais. O trabalho parte do pressuposto de que ao explicitar a relação entre seres humanos e animais é possível integrar e promover uma EA mais crítica, assim como contribuir para aulas de Biologia mais contextualizadas e significativas. A complexidade presente é pontual, de forma que as discussão acerca do tema surgem ao referenciar Gadotti. 


\section{C4: planejamento e currículo}

Nessa categoria encontram-se quatro trabalhos (T43, T86, T91 e T111) que tratam dos currículos e práticas político-pedagógicas, assim como propostas que incluem políticas públicas. Também estão presentes trabalhos que analisam os livros didáticos, tomando-os enquanto possíveis promotores de mudanças nos currículos. Assim, por exemplo, T43 discute a dinâmica dos ecossistemas, considerando os conteúdos disciplinares e didáticos. Sugere três aspectos para tratar os ciclos biogeoquímicos, visando organizar o trabalho em sala. A complexidade, ainda que referenciada de forma substancial, não aparece articulada com outras áreas do conhecimento.

T91 analisa o tratamento dado pelos editorais ao tema energia, assim como o modelo socioambiental subjacente. Os livros didáticos analisados são para o $4^{\circ} \mathrm{ESO}$. Para a análise, procuram articular aspectos do conhecimento cotidiano, científico e escolar ao tratar da complexificação do conhecimento (GARCÍA, 1998). Aponta para elementos da perspectiva da complexidade, inclusive incorporando-os como instrumento de análise (T91, p. 64).

T111 discute aspectos da EA e teorias de políticas públicas, propondo um modelo que busca articular esses elementos com participação e diálogo. Ainda que o discurso sobre a complexidade não seja explícito, é possível encontrar elementos que o potencialize (T111, p. 821; T111, p. 828). Destaca-se que a abordagem busca aproximações com o contexto social através da dimensão participativa e dialógica no processo de escolhas dos cidadãos.

\section{C5: reflexões teóricas}

Nessa categoria encontram-se doze trabalhos (T13, T14, T15, T55, T99, T104, T112, T70, T80, T82, T94, T115) voltados às reflexões teóricas, incluindo estado da arte e revisões bibliográficas. Em geral, a preocupação está em discutir referenciais que dão suporte para a reflexão socioambiental. Assim, por exemplo, T13 aponta para a necessidade de refletir sobre a era planetária (MORIN, 2009), tomando como referência as questões socioambientais. A complexidade aparece vinculada ao discurso da criticidade, incertezas e sociedade de risco, na fala de autores como Mayer, Bonil e Pujol e Sauvé.

T55 analisa as ações empresariais ambientais, tecendo comentários sobre a relação de dominação que pode ser estabelecida na escola. A base teórica volta-se à criticidade, representada por Guimarães e Lima. Discute as tendências em EA, a saber: adestramento ambiental; desenvolvimento sustentável; ecologismo radical; e crítica. A complexidade aparece ao tratar da vertente emancipadora, defendida por Lima, e ao identificar as tendências acerca da EA (T55, p. 408).

T112 discute a relação entre interdisciplinaridade e EA crítica à luz das questões epistêmicas, especificamente, sob a perspectiva do materialismo histórico-dialético. Traz reflexões baseadas em Marx, Freire, Loureiro etc. Há trechos no trabalho que mostram o entendimento acerca das questões epistemológicas que envolvem a complexidade. Quando isso ocorre há citações de Morin, Prigogine e Stengers.

T80 realiza um estudo teórico e prático sobre as hipóteses de transição considerando elementos da EA nos temas água e energia. Há preocupação em articular a complexidade com o processo ensino-aprendizagem, considerando referenciais como Investigación y Renovación Escolar (IRES), García, Morín e Naïr, Bonil e Cano. 


\section{Potencialidades para incorporar a perspectiva da complexidade: analisando as produções e suas contribuições para uma formação mais crítica}

Dos trabalhos potenciais à complexidade, cerca de 17\% está em C1, 29\% em C2, 15\% em C3, 10\% em C4, e 29\% em C5. Ou seja, os trabalhos com potencialidades para a complexidade estão concentrados em C2 e C5. O Quadro 1 traz uma síntese das produções que sinalizam para a complexidade. Ele está organizado a partir das colunas: (1) Potencialidade para promover a complexidade; (2) Modelos de aproximações aos discursos sobre EA baseados em Rodríguez-Marín e García (2009); (3) Intencionalidades que explicitam as características gerais das Potencialidades e Modelos; (4) Produçoes brasileiras e espanholas, organizadas a partir de C1,..., C5 e identificadas por T1,..., Tn; e (5) Ideias centrais e palavras-chaves presentes nos trabalhos. Na coluna (1) os trabalhos estão classificados em (i) perspectiva com aproximações pontuais; (ii) perspectiva com potencial - em transição; e (iii) perspectiva com alto potencial - consolidada.

Os dados mostram uma distribuição igualitária entre as produções em (ii) transição e (iii) consolidadas (20\% são produções brasileiras em transição, 20\% são produções espanholas em transição, $20 \%$ são produções brasileiras consolidadas e $20 \%$ são produções espanholas consolidadas). As produções em (i) representam os outros $20 \%$, distribuídas em $12 \%$ de trabalhos brasileiros e 8\% espanhóis. Para ambos os países é notória a concentração de trabalhos em C2 (67\%), que tratam da complexidade de forma ainda tímida. Ou seja, os discursos presentes buscam aproximações pontuais da complexidade, podendo se aproximar dos modelos de EA naturalista, conservacionista e tecnocrática (RODRÍGUEZ-MARÍN; GARCÍA, 2009). Em alguns casos há o reconhecimento da necessidade de uma abordagem mais complexa, no entanto, o discurso aparece apenas como uma forma de trazer à tona um alerta. Não há referências claras e adequadamente discutidas, mas menções e comentários pontuais. Nota-se que na Espanha há uma ligeira preocupação em tratar de reflexões teóricas acerca da questão socioambiental sob um viés ainda muito longe da complexidade.

Quanto aos trabalhos em (ii), com potencial para incorporar a complexidade, ou seja, produções que apontam para uma transição de pensamento e que, no geral, se apoiam em discurso mais críticos baseados nas questões sociais, há uma distribuição igualitária entre as categorias. Apenas cerca de 30\% dos trabalhos em transição estão em C5, ou seja, são trabalhos com foco em reflexões teóricas que, por sua vez, são fundamentais para promover uma mudança de postura de forma embasada. No Brasil, as palavras mais adequadas que justificam a transição voltam-se à criticidade e participação; na Espanha, elas se revertem aos problemas sociocientíficos e crescimento sustentável. Essa variação parece ocorrer devido aos estudos e pesquisas que vem se desenvolvendo ou estão consolidadas em grupos de pesquisas nesses países. Em especial, na Europa o foco atual parece apontar para preocupações com questões sociocientíficas e conceito sobre o decrescimento; no Brasil, os discursos sobre criticidade influenciados por Freire (1987) e autores como Loureiro (2006), Jacobi (2009), Leff (2009), estão mais presentes nos trabalhos.

As produções (iii) com alto potencial ou consolidadas frente ao discurso da complexidade, compreendem um universo de dezesseis produções, tal como os trabalhos em transição. Esse é um dado interessante porque mostra um número elevado de pesquisadores(as) potenciais para ampliação e divulgação da perspectiva da complexidade de forma mais sustentável. Em ambos os países há concentração em C5 (44\% dos trabalhos com alto potencial), o que pode 
ser justificado pela necessidade de ainda se estabelecer e consolidar a perspectiva da complexidade para discutir as questões de natureza aberta e dinâmica. Destacam-se que são poucos os trabalhos em C3 (12\%) que efetivamente podem alterar os discursos dos(as) estudantes em sala de aula. Especificamente, na Espanha há tanto preocupação com a questão mais teórica (C5) quanto com as ideias dos(as) alunos(as) (C2); no Brasil, o foco está em C5, mas há uma pequena amostra que tem interesse na formação de professores(as) (C1). Isso é relevante, visto que a ampliação do discurso mais adequado pode ser influenciado pelos(as) docentes. Quanto às palavras mais representativas, notam-se que poucas são as diferenças entre os dois países. No geral, elas ocorrem devido ao uso de teorias/ideias/propostas de grupos específicos, a exemplo das hipóteses de transição que denota influencia do grupo da Universidad de Sevilla.

No que se refere ao (b), nas produções espanholas foi notória a ausência de discussões da temática socioambiental na Educação Infantil e Primária, ainda que isso apareça nos documentos desse país. As publicações concentram-se na ESO, Bachillerato e Ensino Superior: 36\% da amostra voltados ao ESO, 15\% ao Bachillerato, e 49\% ao Ensino Superior. Quanto às produções brasileiras, 7\% da amostra referem-se ao Nível Primário, 26\% ao Ensino Fundamental, 30\% ao Ensino Médio, e 37\% ao Ensino Superior. Em ambos os países há concentração no Ensino Superior o que pode refletir a maior facilidade dos pesquisadores(as) em promover estudos nos seus centros de pesquisa, ainda que parte dos(as) professores(as) universitários espanhóis também atuem em institutos e escolas secundárias. No geral, notam-se que os trabalhos que tratam das questões mais críticas e complexas estão concentrados nos níveis Ensino Médio, no Brasil, e Secundário, na Espanha. Por fim, é importante notar que as produções publicadas nessas revistas não abrangem muitas discussões do Nível Primário, ainda que essa etapa de ensino seja muito considerada nos documentos dos dois países. É provável que publicações desse nível não ocorram com frequência nas revistas analisadas.

Quadro 1. Características das produções com potencialidade para a complexidade

\begin{tabular}{|c|c|c|c|c|}
\hline $\begin{array}{l}\text { Potencialidade } \\
\text { (para promover } \\
\text { a complexidade) }\end{array}$ & $\begin{array}{c}\text { Modelos } \\
\text { (Aproximações) }\end{array}$ & $\begin{array}{c}\text { Intencio- } \\
\text { nalidades } \\
\text { (Características) }\end{array}$ & $\begin{array}{l}\text { Produ- } \\
\text { ções } \\
\text { (Relação } \\
\text { C e T) }\end{array}$ & $\begin{array}{l}\text { Ideias centrais } \\
\text { (palavras-chave) }\end{array}$ \\
\hline \multirow{3}{*}{$\begin{array}{l}\text { Perspectiva } \\
\text { com } \\
\text { aproximações } \\
\text { pontuais }\end{array}$} & Naturalista & \multirow{2}{*}{$\begin{array}{l}\text { (1) Explicação } \\
\text { dos processos da } \\
\text { natureza; } \\
\text { (2) Conservação } \\
\text { do meio e visão } \\
\text { ecológica; }\end{array}$} & \multirow{2}{*}{ 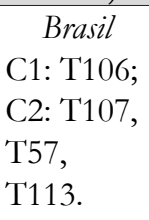 } & \multirow{3}{*}{ 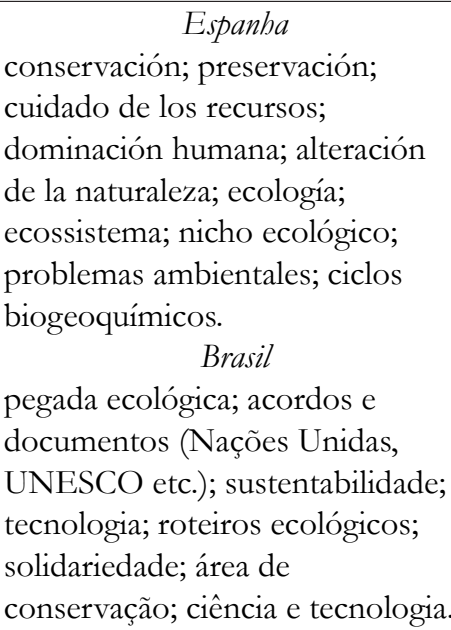 } \\
\hline & Conservacionista & & & \\
\hline & Tecnocrática & $\begin{array}{l}\text { (3) Foco na } \\
\text { manutenção (ou } \\
\text { pouca } \\
\text { alteração) do } \\
\text { sistema } \\
\text { econômico e/ou } \\
\text { empresarial }\end{array}$ & $\begin{array}{l}\text { T17, T31; } \\
\text { C4: T43, } \\
\text { T86. }\end{array}$ & \\
\hline
\end{tabular}

continua 
Quadro 1. continuação

\begin{tabular}{|c|c|c|c|c|}
\hline $\begin{array}{l}\text { Potencialidade } \\
\text { (para promover } \\
\text { a complexidade) }\end{array}$ & $\begin{array}{c}\text { Modelos } \\
\text { (Aproximações) }\end{array}$ & $\begin{array}{c}\text { Intencio- } \\
\text { nalidades } \\
\text { (Características) }\end{array}$ & $\begin{array}{l}\text { Produ- } \\
\text { ções } \\
\text { (Relação } \\
\text { C e T) }\end{array}$ & $\begin{array}{l}\text { Ideias centrais } \\
\text { (palavras-chave) }\end{array}$ \\
\hline $\begin{array}{c}\text { Perspectiva } \\
\text { com potencial } \\
\text { (em transição) }\end{array}$ & Ação social & $\begin{array}{l}\text { Preocupação } \\
\text { com as questões } \\
\text { sociais e } \\
\text { mudanças } \\
\text { pautadas na } \\
\text { criticidade }\end{array}$ & \begin{tabular}{l}
\multicolumn{1}{c}{ Brasil } \\
C1: T50, \\
T58; \\
C2: T68; \\
C3: T52, \\
T100; \\
C4: T111; \\
C5: T55, \\
T70. \\
\\
Espanha \\
C1: T85; \\
C2: T96, \\
T30; \\
C3: T89; \\
C4: T91; \\
C5: T13, \\
T15, T82.
\end{tabular} & \begin{tabular}{l}
\multicolumn{1}{c}{ Espanha } \\
planetariedad; era planetaria; \\
crecimiento sostenible; \\
incertidumbres; sociedad del \\
riesgo; solidariedad; integridad \\
ecológica; justicia social y \\
ecológica; democracia; enfoque \\
interdisciplinar; problemas \\
socio-científicos; responsabilidad \\
social; igualdad-equidad; \\
autonomia; desarrollo humano; \\
ecociudadanía; CTSA; crítica. \\
$\quad$ Brasil \\
tema gerador; pensamento \\
crítico; sociedade de risco; \\
realidade; pensamento \\
emancipatório; processo cíclico; \\
dialogicidade; participativa; \\
práxis; contextualização; aspectos \\
políticos.
\end{tabular} \\
\hline $\begin{array}{l}\text { Perspectiva } \\
\text { com alto } \\
\text { potencial } \\
\text { (consolidada) }\end{array}$ & Integradora & $\begin{array}{l}\text { Foco na } \\
\text { mudança de } \\
\text { postura, } \\
\text { pautando-se na } \\
\text { perspectiva da } \\
\text { complexidade }\end{array}$ & \begin{tabular}{l}
\multicolumn{1}{c}{ Brasil } \\
C1: T49, \\
T128; \\
C2: T75; \\
C3: T47; \\
C5: T99, \\
T104, \\
T112, \\
T115. \\
\\
Espanba \\
C1: T9; \\
C2: T6, \\
T38, T42; \\
C3: T44; \\
C5: T80, \\
T14, T94.
\end{tabular} & \begin{tabular}{l}
\multicolumn{1}{c}{ Espanha } \\
relaciones; hipótesis de \\
transición; mesocosmo; niveles de \\
aprendizaje; tramas de contenidos; \\
pensamiento sistémico; \\
dimensiones; múltiples causalidad; \\
interacción; coevolución; \\
complementariedade; \\
emergencia; processos; \\
crisis; sociedad del riesgo; \\
autoorganización; cibernética; \\
teoría de la información; entropía; \\
recursividad; decrecimiento; \\
\multicolumn{1}{c}{ Brasil } \\
abordagem sistêmica; inter- \\
relações; incerteza; dinâmico; \\
sistemas; indeterminação; \\
crítico; interconexões; práxis; \\
transformação; não-equilíbrio; \\
complexidade científica; entropia.
\end{tabular} \\
\hline
\end{tabular}

Fonte: elaborado pelas autoras. 
Os resultados comentados nos parágrafos anteriores trazem alguns parâmetros que podem subsidiar as ações e reflexões na escola. Com eles é possível realizar apontamentos sobre complexidade vinculados à uma formação mais crítica (FREIRE,1987). O principal desses apontamentos conduz para uma visão mais otimista sobre a inserção/ reflexão/ divulgação da perspectiva da complexidade. Isso se deve à gama expressiva de trabalhos que vem incorporando elementos da complexidade em ações e reflexões, ainda que isso não implique em uma mudança profunda e sustentável de paradigma. É animador identificar grupos, em especial aqueles voltados à perspectiva com potencial e alto potencial para a complexidade, que estão muito próximos de promover atividades e reflexões que levem efetivamente a essa mudança. As atividades propostas na escola (tomando os resultados do Quadro 1) poderiam tratar temas com preocupações sociais, locais e/ou globais que potencializassem uma mudança de postura, considerando, por exemplo, as abordagens sistêmicas, as incertezas, os processos dinâmicos, a interação, a auto-organização, o decrescimento etc.

Outro apontamento refere-se aos espaços possíveis para incorporar a complexidade de forma consistente e sustentável, a ponto de promover uma mudança de paradigma. Nesse sentido, uma dimensão educacional, uma dimensão ensino-aprendizagem e uma dimensão epistemológica pautadas pelos pressupostos da complexidade podem contribuir para essa mudança (WATANABE, 2012). Essas dimensões, mais do que trazer orientações ou receitas prontas, sinalizam para os espaços potencializadores de reflexões e alterações de postura. Assim, na dimensão educacional, em que a preocupação relaciona-se às mudanças de longo prazo que implicam, sobretudo, nas mudanças sociais, parece fundamental para promover alterações na forma de vida e no modelo socioeconômico predominante. Nesse sentido, na escola é essencial conduzir reflexões sobre a visão de mundo já estabelecida, incluindo a científica, para então contrapor novas relações sociais, menos consumista e mais realista, incorporando um conhecimento mais complexo nas resoluções de problemas socioambientais. $\mathrm{Na}$ dimensão ensino-aprendizagem, que se refere às ações concretas dirigidas para a resolução do problema no âmbito escolar e de sala de aula, parece importante pensar na organização e seleção de conteúdos que estejam conectados à questão temática como a socioambiental. Além disso, a complexidade nessa dimensão está relacionada com elementos e aspectos da aprendizagem que contribuem para uma prática docente pautada na complexificação do conhecimento (GARCÍA, 1998) e no pensamento complexo (MORIN, 2007). Na dimensão epistemológica, que se refere à seleção de conteúdos conceituais considerando a estrutura dos conhecimentos e a sua importância nas teorias, parece fundamental repensar a perspectiva do conhecimento científico que, no caso da problemática socioambiental, pode incorporar o tratamento das questões longe do equilíbrio, de problemas dinâmicos e complexos.

\section{Considerações finais}

As questões socioambientais demandam uma outra forma de tratamento que, do nosso ponto de vista, volta-se à perspectiva da complexidade. Nesse sentido, esse artigo buscou identificar como tal discurso vem sendo incorporados nos trabalhos de pesquisas no Brasil e na Espanha. A intenção foi apresentar ações e reflexões que tem potencial para inserir a perspectiva da complexidade, seja no contexto mais local ou global, de natureza mais prática ou teórica/ reflexiva. Com essa pesquisa foi possível identificar uma tendência de mudança de discurso, seja 
Aspectos da complexidade nas questões socioambientais: ...

pontual, em transição ou consolidada. De forma geral, essa mudança ainda parece tímida frente às questões mais profundas que devem ser consideradas, mas indicam algum caminho. Uma mudança promissora na forma de lidar com a perspectiva da complexidade requer incorporá -la na Dimensão Educacional, Dimensão Ensino-Aprendizagem e Dimensão Epistemológica (WATANABE, 2012).

Com essa reflexão espera-se ter contribuído para que as ações escolares futuras incorporem mais elementos da complexidade de forma sustentável e efetiva, promovendo uma formação mais crítica, complexa e reflexiva. Além disso, há de se considerar que os resultados aqui obtidos são promissores, pois sinalizam para mudanças, ainda que tímidas, na forma de tratar as questões de natureza socioambiental, considerando-as dinâmicas e com potencialidades para uma formação mais crítica.

\section{Agradecimentos}

Esse trabalho foi financiado pela Fundação de Amparo à Pesquisa do Estado de São Paulo (Fapesp), agência de fomento à qual agradecemos.

\section{Referências}

BECK, U. A reinvenção da política: rumo a uma teoria da modernização reflexiva. In: BECK, U.; GIDDENS, A. Modernização reflexiva. São Paulo: Ed. Unesp, 1997. p. 11-72.

BRASIL. Decreto $\mathbf{n}^{\circ}$ 4.281, de 25 de junho de 2002. Regulamenta a lei $n^{\circ} 9.795$, de 27 de abril de 1999, que institui a política nacional de educação ambiental, e dá outras providências. Brasília, 2002. Disponível em: < http://www.planalto.gov.br/ccivil_03/decreto/2002/d4281. htm>. Acesso em: 7 ago. 2018.

BRASIL. Lei $\mathbf{n}^{\circ} \mathbf{9 . 7 9 5}$, de 27 de abril de 1999. Dispõe sobre a educação ambiental, institui a política nacional de educação ambiental e dá outras providências. Brasília, 1999. Disponível em: <http://www.mma.gov.br/port/conama/legiabre.cfm?codlegi=321>. Acesso em: 7 ago. 2018.

BRASIL. Ministério da Educação. Parâmetros curriculares nacionais: ciências da natureza, matemática e suas tecnologias. Brasília, 2000.

BRASIL. Ministério da Educação. PCN+ ensino médio: orientações educacionais complementares aos parâmetros curriculares nacionais ciências da natureza, matemática e suas tecnologias. Brasília, 2002.

BRASIL. Ministério da Educação. Conselho Nacional de Educação. Resolução no 2, de 15 de junho de 2012. Estabelece as diretrizes curriculares nacionais para a educação ambiental. Brasília, 2012. Disponível em: <https://tinyurl.com/ychskd3e>. Acesso em: 7 ago. 2018. 
CARVALHO, I. C. M. Educação ambiental crítica: nomes e endereçamentos da educação. In: BRASIL. Ministério do Meio Ambiente. Identidades da educação ambiental brasileira. Brasília, 2004. p. 13-24. Disponível em: <http:/ /www.mma.gov.br/estruturas/educamb/_ arquivos/livro_ieab.pdf>. Acesso em: 7 ago. 2018.

ESPANHA. Decreto 428/2008, de 29 de julio, por el que se establece la ordenación y las enseñanzas correspondientes a la educación infantil en Andalucía. Boletín Oficial de la Junta de Andalucía, Sevilla, n. 164, 19 ago. 2008. Disponível em: < https:/ /www. juntadeandalucia.es/boja/2008/164/2>. Acesso em: 9 ago. 2018.

ESPANHA. Ley Orgánica 2/2006, de 3 de mayo, de Educación. Boletín Oficial del Estado, Madrid, n. 106, p. 17158-17207, 4 mayo 2006. Disponível em: <https://www.boe. es/buscar/doc.php?id=BOE-A-2006-7899>. Acesso em: 9 ago. 2018.

ESPANHA. Ley Orgánica 8/2013, de 9 de diciembre, para la mejora de la calidad educativa. Boletín Oficial del Estado, Madrid, n. 295, 10 dic. 2013. Disponível em: <https:/ /www. boe.es/buscar/pdf/2013/BOE-A-2013-12886-consolidado.pdf>. Acesso em: 9 ago. 2018.

ESPANHA. Orden de 10 de agosto de 2007, por la que se desarrolla el currículo correspondiente a la educación secundaria obligatoria en Andalucía. Boletín Oficial de la Junta de Andalucía, Sevilla, n. 171, 30 ago. 2007. Disponível em: <https://www. juntadeandalucia.es/boja/2007/171/2>. Acesso em: 9 ago. 2018.

ESPANHA. Orden de 17 de marzo de 2015, por la que se desarrolla el currículo correspondiente a la educación primaria en Andalucía. Boletín Oficial de la Junta de Andalucía, Sevilla, n. 60, 27 mar. 2015. Disponível em: < https://www.juntadeandalucia.es/ boja/2015/60/1>. Acesso em: 9 ago. 2018.

FREIRE, P. Pedagogia do oprimido. 17. ed. Rio de Janeiro: Paz e Terra, 1987.

GARCÍA, J. E. Hacia una teoría alternativa sobre los contenidos escolares. Sevilla: Díada, 1998.

GUIMARÃES, M. Educação ambiental crítica. In: In: BRASIL. Ministério do Meio Ambiente. Identidades da educação ambiental brasileira. Brasília, 2004. p. 25-34. Disponível em: <http://www.mma.gov.br/estruturas/educamb/_arquivos/livro_ieab.pdf>. Acesso em: 7 ago. 2018.

JACOBI, P. R. Educação e sustentabilidade: caminhos e práticas para uma educação transformadora. São Paulo: Evoluir Cultural, 2009.

LEFF, E. Saber ambiental: sustentabilidade, racionalidade, complexidade, poder. Petrópolis: Vozes, 2009.

LOUREIRO, C. F. B. Trajetória e fundamentos da educação ambiental. São Paulo: Cortez, 2006.

MORAES, R.; GALIZAZZI, M. C. Análise textual discursiva. Ijuí: Ed. Unijuí, 2007.

MORIN, E. Introdução ao pensamento complexo. 3. ed. Porto Alegre: Sulina, 2007. 
PRIGOGINE, I. O fim das certezas: tempo, caos e as leis a natureza. São Paulo: Ed. Unesp, 1996.

RODRÍGUEZ-MARÍN, F; GARCÍA, J. E. El activismo que no cesa: obstáculos para incorporar la metodología didáctica basada en la investigación del alumno a la práctica de la educación ambiental. Invetigacion en la Escuela, Sevilla, v. 67, p. 23-36, 2009.

WATANABE, G. Aspectos da complexidade: contribuições da física para a compreensão do tema ambiental. 2012. 246 f. Tese (Doutorado em Ensino de Ciências) - Instituto de Física, Faculdade de Educação, Universidade de São Paulo, São Paulo, 2012.

Anexo A. Produções espanhola e brasileira potenciais para discutir a complexidade

\begin{tabular}{|c|c|c|c|c|c|}
\hline $\mathbf{R}$ & $T$ & Ano & Título & Autor(es) & $\mathrm{C}$ \\
\hline \multirow{3}{*}{$\mathrm{R} 1$} & T6 & 2012 & $\begin{array}{l}\text { Los procesos de construcción del conocimiento } \\
\text { significativo del agua en bachillerato: estudio de casos }\end{array}$ & J. F. Arroyo & $\mathrm{C} 2$ \\
\hline & T9 & 2014 & $\begin{array}{l}\text { Competencias profesionales en educación para la } \\
\text { sostenibilidad: un estudio exploratorio de la visión de } \\
\text { futuros maestros }\end{array}$ & $\begin{array}{l}\text { G. Cebrián; M. J. } \\
\text { Pubill }\end{array}$ & $\mathrm{C} 1$ \\
\hline & $\mathrm{T} 80$ & 2014 & $\begin{array}{l}\text { Las hipótesis de transición como herramienta didáctica } \\
\text { para la educación ambiental }\end{array}$ & $\begin{array}{l}\text { F. R. Marín; J. F. } \\
\text { Arroyo; J. E. G. Díaz }\end{array}$ & $\mathrm{C} 5$ \\
\hline \multirow{8}{*}{$\mathrm{R} 2$} & T13 & 2010 & Educación ambiental y ciudadanía planetaria & $\begin{array}{l}\text { M. Novo; M. Á. } \\
\text { Murga }\end{array}$ & $\mathrm{C} 5$ \\
\hline & T14 & 2010 & $\begin{array}{l}\text { Educación para la sostenibilidad desde la perspectiva de la } \\
\text { complejidad }\end{array}$ & $\begin{array}{l}\text { J. Bonil, M. Junyent; } \\
\text { R.M. Pujol }\end{array}$ & $\mathrm{C} 5$ \\
\hline & T15 & 2010 & $\begin{array}{l}\text { Educar para la sostenibilidad: un problema del que } \\
\text { podemos hacernos cargo }\end{array}$ & T. Prieto; E. España & $\mathrm{C} 5$ \\
\hline & T16 & 2010 & $\begin{array}{l}\text { Evolución de las percepciones medioambientales de los } \\
\text { alumnos de educación secundaria en un curso académico }\end{array}$ & M. Jaén; P. Barbudo & $\mathrm{C} 2$ \\
\hline & T17 & 2010 & $\begin{array}{l}\text { La comprensión de conceptos de ecología y sus } \\
\text { implicaciones para la educación ambiental }\end{array}$ & $\begin{array}{l}\text { F. J. S. Sánchez- } \\
\text { Cañete; A. P. } \\
\text { Pedrajas }\end{array}$ & $\mathrm{C} 2$ \\
\hline & $\mathrm{T} 82$ & 2015 & $\begin{array}{l}\text { Dimensión ética de la sostenibilidad curricular en el } \\
\text { sistema de evaluación de las aulas universitarias: el caso de } \\
\text { la enseñanza aprendizaje de las ciencias }\end{array}$ & $\begin{array}{l}\text { R. Jiménez- } \\
\text { Fontana; E. } \\
\text { García-GonzEalez; } \\
\text { P. Azcárate; } \\
\text { A.Navarrete }\end{array}$ & $\mathrm{C} 5$ \\
\hline & T85 & 2015 & $\begin{array}{l}\text { Un instrumento para analizar las actividades prácticas } \\
\text { en la formación inicial del profesorado de secundaria } \\
\text { de ciencias y matemáticas desde la perspectiva de la } \\
\text { sostenibilidad }\end{array}$ & $\begin{array}{l}\text { J. M. C. Domingo; J. } \\
\text { C. Fernández; P. A. } \\
\text { Goded }\end{array}$ & $\mathrm{C} 1$ \\
\hline & T86 & 2015 & $\begin{array}{l}\text { ¿Qué características presentan los contenidos } \\
\text { relacionados con las problemáticas ambientales } \\
\text { propuestos en los libros de texto de 3o de la ESO? }\end{array}$ & $\begin{array}{l}\text { S. M. Bayonas; M. J. } \\
\text { García }\end{array}$ & $\mathrm{C} 4$ \\
\hline
\end{tabular}


Anexo A. continuação

\begin{tabular}{|c|c|c|c|c|c|}
\hline $\mathbf{R}$ & $\mathbf{T}$ & Ano & Título & Autor(es) & $\mathrm{C}$ \\
\hline \multirow{2}{*}{$\mathrm{R} 3$} & T30 & 2010 & $\begin{array}{l}\text { Retos y dificultades para una educación ambiental } \\
\text { informal }\end{array}$ & F. J. Perales & $\mathrm{C} 2$ \\
\hline & T31 & 2010 & $\begin{array}{l}\text { El grupo de discusión como técnica para analizar los } \\
\text { discursos sobre cuestiones medioambientales }\end{array}$ & J. Ibarra; J. Arlegui & $\mathrm{C} 2$ \\
\hline \multirow{8}{*}{$\mathrm{R} 4$} & T38 & 2010 & Investigando el agua en bachillerato & J. F. Arroyo & $\mathrm{C} 2$ \\
\hline & T42 & 2011 & $\begin{array}{l}\text { El agua como recurso para investigar en el aula: una } \\
\text { investigación en la asignatura de ciencias para el mundo } \\
\text { contemporáneo }\end{array}$ & $\begin{array}{l}\text { J. F. Arroyo; E. S. } \\
\text { Ramirez }\end{array}$ & $\mathrm{C} 2$ \\
\hline & $\mathrm{T} 43$ & 2013 & $\begin{array}{l}\text { El papel de los ciclos biogeoquímicos en el estudio de los } \\
\text { problemas ambientales en educación secundaria }\end{array}$ & P. Esteve; M. Jaén & $\mathrm{C} 4$ \\
\hline & T44 & 2013 & $\begin{array}{l}\text { La elaboración de materiales didácticos: una herramienta } \\
\text { para la investigación educativa }\end{array}$ & $\begin{array}{l}\text { J. F. Arroyo; E. S. } \\
\text { Ramirez }\end{array}$ & $\mathrm{C} 3$ \\
\hline & T89 & 2014 & $\begin{array}{l}\text { Educación ambiental y enfoque de género, claves para su } \\
\text { integración }\end{array}$ & $\begin{array}{l}\text { D. L. Domínguez; C. } \\
\text { S. Espallargas }\end{array}$ & $\mathrm{C} 3$ \\
\hline & T91 & 2015 & $\begin{array}{l}\text { Energía, problemas socioambientales y libros de texto: } \\
\text { ¿una relación compleja? }\end{array}$ & $\begin{array}{l}\text { L. López-Lozano; E. } \\
\text { S. Ramírez }\end{array}$ & $\mathrm{C} 4$ \\
\hline & T94 & 2015 & $\begin{array}{l}\text { El huerto escolar ecológico como herramienta para la } \\
\text { educación en y para el decrecimiento }\end{array}$ & $\begin{array}{l}\text { F. R. Marín; J. F. } \\
\text { Arroyo; J. E. G. Díaz }\end{array}$ & $\mathrm{C} 5$ \\
\hline & T96 & 2015 & $\begin{array}{l}\text { Ciudadanía, participación y compromiso con los } \\
\text { problemas socio-ambientales: concepciones del alumnado } \\
\text { participante en programas educativos andaluces }\end{array}$ & $\begin{array}{l}\text { O. Moreno- } \\
\text { Fernández; F. F. } \\
\text { García-Pérez }\end{array}$ & $\mathrm{C} 2$ \\
\hline
\end{tabular}


Anexo A. continuação

\begin{tabular}{|c|c|c|c|c|c|}
\hline $\mathbf{R}$ & $\mathbf{T}$ & Ano & Título & Autor(es) & C \\
\hline \multirow{9}{*}{$\mathrm{R} 5$} & T47 & 2011 & $\begin{array}{l}\text { Concepções sistêmicas na educação ambiental: uma } \\
\text { experiência com alunos do ensino fundamental }\end{array}$ & $\begin{array}{l}\text { C. M. Palácios; R. A. } \\
\text { Dal -Farra; M. Geller }\end{array}$ & $\mathrm{C} 3$ \\
\hline & T49 & 2012 & $\begin{array}{l}\text { Desafios e possibilidades para a abordagem de temas } \\
\text { ambientais em aulas de física }\end{array}$ & $\begin{array}{l}\text { G. W. Caramello; } \\
\text { R. B. Strieder; S. T. } \\
\text { Gehlen }\end{array}$ & C1 \\
\hline & T50 & 2012 & $\begin{array}{l}\text { Discursos de educação ambiental produzidos por } \\
\text { professores em formação continuada }\end{array}$ & $\begin{array}{l}\text { L. M. F. Santos; R. L. } \\
\text { Bozelli; M. Espinet; } \\
\text { I. Martins }\end{array}$ & C1 \\
\hline & T52 & 2013 & $\begin{array}{l}\text { Controvérsias socioambientais no contexto da construção } \\
\text { de sentidos sobre relações entre energia e ambiente na } \\
\text { escola }\end{array}$ & A. Cose; I. Martins & C3 \\
\hline & T99 & 2014 & Educação ambiental e temas controversos & $\begin{array}{l}\text { R. A. Ribeiro; M. R. } \\
\text { D. Kawanura }\end{array}$ & $\mathrm{C} 5$ \\
\hline & T100 & 2014 & $\begin{array}{l}\text { A educação ambiental no ensino de biologia e um olhar } \\
\text { sobre as formas de relação entre seres humanos e animais }\end{array}$ & $\begin{array}{l}\text { A. R. F. Rodrigues; } \\
\text { C. E. Laburú }\end{array}$ & C3 \\
\hline & T104 & 2014 & $\begin{array}{l}\text { Uma educação na perspectiva ambiental crítica, complexa } \\
\text { e reflexiva }\end{array}$ & $\begin{array}{l}\text { G. Watanabe; M. R. } \\
\text { D. Kawamura }\end{array}$ & $\mathrm{C} 5$ \\
\hline & T106 & 2015 & $\begin{array}{l}\text { Formação em educação para o desenvolvimento } \\
\text { sustentável: um estudo com professores de ciências da } \\
\text { natureza }\end{array}$ & $\begin{array}{l}\text { L. C. Santos; R. } \\
\text { M. G. Silva; M. A. } \\
\text { Pedrosa }\end{array}$ & C1 \\
\hline & T107 & 2015 & $\begin{array}{l}\text { As percepções de educação ambiental e meio ambiente de } \\
\text { professoras das séries finais e a influencia destas em suas } \\
\text { práticas docentes }\end{array}$ & $\begin{array}{l}\text { E. M. Wollmann; F. } \\
\text { A. A. Soares; P. V. } \\
\text { Ilha }\end{array}$ & $\mathrm{C} 2$ \\
\hline
\end{tabular}


Anexo A. continuação

\begin{tabular}{|c|c|c|c|c|c|}
\hline $\mathbf{R}$ & $\mathbf{T}$ & Ano & Título & Autor(es) & $\mathrm{C}$ \\
\hline \multirow{8}{*}{ R6 } & T55 & 2010 & $\begin{array}{l}\text { Empresariado e ambiente: algumas considerações sobre a } \\
\text { educação ambiental no espaço }\end{array}$ & C. M. Bagnolo & $\mathrm{C} 5$ \\
\hline & T57 & 2011 & $\begin{array}{l}\text { Educação ambiental: reflexões sobre a prática de um } \\
\text { grupo de professores de química }\end{array}$ & $\begin{array}{l}\text { R. F. Leite; M. A. } \\
\text { Rodrigues }\end{array}$ & $\mathrm{C} 2$ \\
\hline & T58 & 2011 & $\begin{array}{l}\text { A (re) construção dos conceitos de natureza, meio } \\
\text { ambiente e educação ambiental por professores de duas } \\
\text { escolas públicas }\end{array}$ & $\begin{array}{l}\text { A. M. Lima; H. T. } \\
\text { Oliveira }\end{array}$ & C1 \\
\hline & T68 & 2014 & $\begin{array}{l}\text { Percepção sobre meio ambiente por alunos das séries } \\
\text { iniciais do ensino fundamental: considerações à luz de } \\
\text { Marx e de Paulo Freire }\end{array}$ & $\begin{array}{l}\text { L. S. Garrido; R. M. } \\
\text { S. Meirelles }\end{array}$ & $\mathrm{C} 2$ \\
\hline & T111 & 2014 & $\begin{array}{l}\text { Da pedagogia à política e da política à pedagogia: uma } \\
\text { abordagem sobre a construção de políticas públicas em } \\
\text { educação ambiental no Brasil }\end{array}$ & $\begin{array}{l}\text { D. F. Andrade; A. Q. } \\
\text { Luca; M. Castellano; } \\
\text { C. G. Rissato; M. } \\
\text { Sorrentino }\end{array}$ & $\mathrm{C} 5$ \\
\hline & T112 & 2015 & $\begin{array}{l}\text { Interdisciplinaridade e educação ambiental crítica: } \\
\text { questões epistemológicas a partir do materialismo } \\
\text { histórico-dialético }\end{array}$ & $\begin{array}{l}\text { C. A. S. Costa; C. F. } \\
\text { B. Loureiro }\end{array}$ & $\mathrm{C} 5$ \\
\hline & T113 & 2015 & $\begin{array}{l}\text { Potencial das atividades de uso público do Núcleo } \\
\text { Picinguaba do Parque Estadual da Serra do Mar (SP) para } \\
\text { uma educação ambiental crítica }\end{array}$ & $\begin{array}{l}\text { M. W. Valenti; V. G. } \\
\text { Iared; H. T. Oliveira }\end{array}$ & $\mathrm{C} 2$ \\
\hline & T115 & 2016 & $\begin{array}{l}\text { Análise de dissertações e teses brasileiras de educação } \\
\text { ambiental: compreensões elaboradas sobre o tema } \\
\text { "mudanças climáticas" }\end{array}$ & D. A. Reis; L. F. Silva & $\mathrm{C} 5$ \\
\hline R7 & T70 & 2011 & $\begin{array}{l}\text { Ensino de química e ambiente: as articulações presentes } \\
\text { na revista Química Nova na Escola (QNESC) }\end{array}$ & $\begin{array}{l}\text { R. M. Latini; A. C. } \\
\text { Sousa }\end{array}$ & $\mathrm{C} 5$ \\
\hline \multirow[b]{2}{*}{$\mathrm{R} 8$} & T75 & 2011 & $\begin{array}{l}\text { Algumas compreensões de licenciandos em física sobre o } \\
\text { fenômeno das mudanças climáticas }\end{array}$ & $\begin{array}{l}\text { D. A. Reis; L. F. Silva; } \\
\text { A. Pina }\end{array}$ & $\mathrm{C} 2$ \\
\hline & T128 & 2016 & $\begin{array}{l}\text { Educação CTS e educação ambiental: ações na formação } \\
\text { de professores }\end{array}$ & $\begin{array}{l}\text { R. B. Strieder; G. } \\
\text { Watanabe; K. M. A. } \\
\text { Silva; G. Watanabe }\end{array}$ & C1 \\
\hline
\end{tabular}

R: Revistas e periódicos apresentados "Recorte Metodológico"; T: trabalhos; Ano: ano de publicação do artigo; Titulo: título da publicação; Autor(es): autor(es) da publicação; C: categorias apresentadas "Recorte Metodológico".

Fonte: elaborado pelas autoras.

Artigo recebido em 03/11/2017. Aceito em 22/03/2018.

Contato: Universidade Federal do ABC, CCNH, Avenida dos

Estados, 5001, 09210-170, Santo André, SP, Brasil. 